\title{
Zinc and Flunitrazepam Modulation of GABA-Mediated Currents in Rat Suprachiasmatic Neurons
}

\author{
G. J. STRECKER, W. K. PARK, AND F. E. DUDEK \\ Department of Anatomy and Neurobiology, Colorado State University, Fort Collins, Colorado 80523-1670
}

\begin{abstract}
Strecker, G. J., W. K. Park, and F. E. Dudek. Zinc and flunitrazepam modulation of GABA-mediated currents in rat suprachiasmatic neurons. J. Neurophysiol. 81: 184-191, 1999. The suprachiasmatic nucleus $(\mathrm{SCN})$ of the hypothalamus is responsible for generating circadian rhythms in mammals, and GABA is the predominant neurotransmitter in the SCN. Properties of $\gamma$-aminobutyric acid-A $\left(\mathrm{GABA}_{\mathrm{A}}\right)$ responses in $\mathrm{SCN}$ neurons were examined in acutely prepared hypothalamic slices from 3- to 8-wk-old rats with the use of whole cell voltage-clamp techniques. $\mathrm{Zn}^{2+}$ reduced the amplitude of $\mathrm{GABA}_{\mathrm{A}}$-mediated spontaneous inhibitory postsynaptic currents (sIPSCs) in a concentration-dependent manner ranging from a reduction of control amplitude to $88 \%$ at $10 \mu \mathrm{M}$ to $27 \%$ at $1,000 \mu \mathrm{M}$. $\mathrm{Zn}^{2+}$ reduced IPSC amplitude to a similar degree in the presence of tetrodotoxin and also significantly reduced the amplitude of currents evoked by application of exogenous GABA (100 $\mu \mathrm{M}$, pressure applied). $\mathrm{Zn}^{2+}$ increased the frequency of IPSCs at lower concentrations and decreased it at higher ones. Flunitrazepam ( $100 \mathrm{nM})$ usually failed to potentiate the amplitude of sIPSCs, but prolonged sIPSC kinetics. Two exponential components were normally resolved in the sIPSC decay constants, and flunitrazepam significantly increased those two components. Thus flunitrazepam increased the duration of sIPSCs and potentiated the amplitude of currents evoked by pressure application of GABA. $\mathrm{Zn}^{2+}$ and benzodiazepine each modulated the effect of GABA in nearly all cells, suggesting that most SCN neurons have a similar $\mathrm{GABA}_{\mathrm{A}}$ receptor subunit composition in this respect. $\mathrm{Zn}^{2+}$ also affected sIPSC frequency, which suggests that $\mathrm{Zn}^{2+}$ increased neuronal firing rate at lower concentrations. These results begin to define the cellular roles that these $\mathrm{GABA}_{\mathrm{A}}$ receptor modulators might play in circadian regulation.
\end{abstract}

\section{INTRODUCTION}

Many if not all neurons in the suprachiasmatic nucleus ( $\mathrm{SCN}$ ) contain $\gamma$-aminobutyric acid (GABA) (Moore and Speh 1993; van den Pol 1986), and $\mathrm{GABA}_{\mathrm{A}}$ receptor ligands are known to have effects on this nucleus (for review see Meijer and Rietveld 1989; Rusak and Bina 1990). Both $\mathrm{GABA}_{\mathrm{A}}$ and $\mathrm{GABA}_{\mathrm{B}}$ receptor subtypes have been identified in the $\mathrm{SCN}$. The $\mathrm{GABA}_{\mathrm{A}}$ receptor agonist muscimol is known to produce phase shifts in vivo (Smith et al. 1989). Fast, inhibitory postsynaptic potentials (IPSPs) and currents (IPSCs ) mediated by $\mathrm{GABA}_{\mathrm{A}}$ receptors have been analyzed in SCN neurons (e.g., Jiang et al. 1997; Kim and Dudek 1992), and several lines of electrophysiological evidence support the hypothesis that SCN neurons form an interconnected network of GABAergic synapses (Strecker et al.

The costs of publication of this article were defrayed in part by the payment of page charges. The article must therefore be hereby marked "advertisement" in accordance with 18 U.S.C. Section 1734 solely to indicate this fact.
1997). Recent data suggest that activation of $\mathrm{GABA}_{\mathrm{A}}$ receptors leads to depolarization and excitation of SCN neurons during the day, compared with the traditional hyperpolarizing responses during the night (Wagner et al. 1997). This effect, if present, would not only tend to synchronize the activity of SCN neurons during the day, but would also augment the peak (day) and trough (night) of the circadian rhythm of electrical activity of SCN neurons. Although these data on the effects of GABA are controversial (e.g., Gribkoff et al. 1997; Strecker et al. 1998), interest concerning $\mathrm{GABA}_{\mathrm{A}}$-receptor mechanisms and their role in regulating circadian rhythms has continued to expand.

Benzodiazepines, which can modulate $\mathrm{GABA}_{\mathrm{A}}$ receptor function through distinct binding sites, inhibit neuronal firing in SCN neurons in vitro (Bos and Mirmiran 1993; Liou et al. 1990; Mason et al. 1991) and affect phase shifts in vivo (Ralph and Menaker 1986, 1989; for review see Morin 1991; Turek and Van Reeth 1988). The wide clinical use of benzodiazepines and the possibility of relating the effects of specific benzodiazepines to particular $\mathrm{GABA}_{\mathrm{A}}$ receptor subtypes has enhanced interest in their pharmacological actions in the circadian system. The previous observation that $\mathrm{GABA}_{\mathrm{A}^{-}}$ receptor-mediated responses of cultured rat $\mathrm{SCN}$ neurons were insensitive to diazepam (Kawahara et al. 1993) has lead us to examine the effects of the widely used benzodiazepine flunitrazepam on GABA-mediated responses of SCN neurons in hypothalamic slices from adult rats. Considerable interest has also recently focused on the role of $\mathrm{Zn}^{2+}$ as a modulator of $\mathrm{GABA}_{\mathrm{A}}$ receptors, particularly because $\mathrm{Zn}^{2+}$ is thought to be released under physiological and pathological conditions in structures such as the hippocampus. $\mathrm{Zn}^{2+}$ has been reported to be present in the SCN, possibly in a synaptically releasable pool (Huang et al. 1993). Furthermore, $\mathrm{Zn}^{2+}$ is thought to modulate A-current in SCN neurons (Huang et al. 1993), so it may regulate firing rate during the circadian rhythm. Thus $\mathrm{GABA}_{\mathrm{A}}$-receptor modulation by substances such as $\mathrm{Zn}^{2+}$ and benzodiazepines offer multiple avenues for the experimental manipulation of circadian rhythmicity. However, the mechanism and site of action of $\mathrm{GABA}_{\mathrm{A}^{-}}$ receptor modulators in many previous experiments have been difficult to assess, and little is known about their cellular effects at the membrane level in the SCN. In spite of the potential importance of these $\mathrm{GABA}_{\mathrm{A}}$-receptor modulators for regulation of circadian rhythms, there are discrepancies in the literature regarding their actions on SCN neurons.

The effects of benzodiazepines and $\mathrm{Zn}^{2+}$ on $\mathrm{GABA}_{\mathrm{A}}$ receptors are sometimes interrelated, making it useful to investigate the effects of both substances. $\mathrm{GABA}_{\mathrm{A}}$ receptors in the CNS are heteromultimers, with different brain regions 
containing receptors composed of different subunits (Wisden et al. 1992), and some combinations of GABA receptor subunits can produce distinct functional properties (Verdoorn et al. 1990; for review see Sieghart 1992). The level of sensitivity of $\mathrm{GABA}_{\mathrm{A}}$ receptors to both zinc and benzodiazepines is related in part to whether $\gamma_{2}$ subunits are present (Draguhn et al. 1990; Pritchett et al. 1989). GABA currents in cultured rat SCN neurons were reported to be blocked noncompetitively ( $\left.\mathrm{IC}_{50} 2 \mu \mathrm{M}\right)$ by $\mathrm{Zn}^{2+}$ and were insensitive to the benzodiazepine diazepam (Kawahara et al. 1993). In contrast, dissociated SCN neurons from immature rats had $\mathrm{GABA}_{\mathrm{A}}$ receptors that were potentiated by benzodiazepine (Shimura et al. 1996), although sensitivity to $\mathrm{Zn}^{2+}$ was not examined. Thus the functional characteristics of these receptors in the SCN are not yet well understood, particularly in mature animals. Here we probe the pharmacology of $\mathrm{GABA}_{\mathrm{A}}$ receptors in SCN neurons in the acute slice preparation with the aim of understanding the mechanisms of action of these two potential modulators of circadian function.

\section{METHODS}

\section{Preparation of slices}

Sprague-Dawley male rats (21- to 60-days old; Harlan, Indianapolis, IN) were housed in a vivarium under a $12 \mathrm{~h}$ light-dark cycle. Experiments were conducted between 5:50-13:10 circadian time (CT). Animals were anesthetized with halothane and decapitated, brains removed, and coronal slices $(180-300 \mu \mathrm{m})$ of hypothalamus cut with the use of a Vibratome (Pelco 101, Ted Pella, Redding, $\mathrm{CA})$ in cold $\left(1-4^{\circ} \mathrm{C}\right)$ artificial cerebrospinal fluid (ACSF) containing (in mM) $125 \mathrm{NaCl}, 2.5 \mathrm{KCl}, 1 \mathrm{CaCl}_{2}, 1 \mathrm{MgCl}_{2}, 24$ $\mathrm{NaHCO}_{3}$, and 10 glucose, bubbled continuously with a mixture of $5 \% \mathrm{CO}_{2}-95 \% \mathrm{O}_{2}(\mathrm{pH} 7.4)$. Slices were stored in ACSF at $34^{\circ} \mathrm{C}$ after cutting. After $\geq 1 \mathrm{~h}$ of storage, slices were placed in a recording chamber mounted on the stage of an upright microscope (Optiphot, Nikon) and continuously perfused with ACSF at 22$24^{\circ} \mathrm{C}$ or $30-32^{\circ} \mathrm{C}$. Individual SCN neurons could be clearly distinguished using a water immersion objective (Olympus $\times 40)$ with Nomarski differential interference contrast optics and a cooled charge-coupled device (CCD) video camera (Paultek Imaging, Grass Valley, CA).

For drug addition, flunitrazepam was dissolved in dimethyl sulfoxide (DMSO) and then diluted further into the bath ACSF. Final DMSO concentrations were typically $0.001 \%$, levels not expected to influence GABA responses (Puia et al. 1991). $\mathrm{Zn}^{2+}\left(\mathrm{ZnCl}_{2}\right.$ or in some experiments $\mathrm{ZnSO}_{4}$ ) was dissolved directly into the bath ACSF at the final concentration $(10-1000 \mu \mathrm{M})$. In some experiments tetrodotoxin (TTX; $1-3 \mu \mathrm{M}$ ) was added to the ACSF to block action potential-dependent synaptic release, thereby isolating postsynaptic mechanisms of modulation. For exogenous application, GABA was dissolved in ACSF and pressure-applied (approximately once per 15-30 s) onto neurons with a Picospritzer (General Valve) through a second patch pipette. Spontaneous $\mathrm{GABA}_{\mathrm{A}}$-mediated IPSCs were observed in essentially all SCN neurons, while spontaneous glutamate-mediated excitatory postsynaptic currents (EPSCs) were seen in fewer cells and at a much lower frequency (Strecker et al. 1997). Although EPSCs were readily distinguishable from IPSCs, many experiments were conducted with DL-2-amino-5-phosphonopentanoic acid (AP5; 10-20 $\mu \mathrm{M}$ ) and 6,7-dinitroquinoxaline-2,3 $(1 h, 4 h)$-dione (DNQX; 10-30 $\mu \mathrm{M})$ to block any glutamatergic synaptic events. Bicuculline methiodide (BIC; $1-20 \mu \mathrm{M}$ ) was added in some experiments to block $\mathrm{GABA}_{\mathrm{A}}$-receptor-mediated inhibition. All chemicals were purchased from Sigma except flunitrazepam, which was purchased from Research Biochemicals.

\section{Electrophysiological recording and analysis}

Patch pipettes were pulled from glass capillaries ( $\mathrm{P}-87$ puller, Sutter Instruments, San Rafael, CA; KG-33 borosilicate, Garner Glass, Claremont, CA). Pipette resistance was 3-5 $\mathrm{M} \Omega$. The pipette solution contained (in $\mathrm{mM}$ ) $130 \mathrm{KCl}, 1 \mathrm{CaCl}_{2}, 1 \mathrm{MgCl}_{2}$, $1 \mathrm{NaCl}, 5$ ethylene glycol-bis ( $\beta$-aminoethyl ether) $-N, N, N^{\prime}, N^{\prime}$ tetraacetic acid (EGTA), $2 \mathrm{Mg}$-ATP (brought to $\mathrm{pH} 7.2$ with $\mathrm{KOH}$ ) to shift $E_{\mathrm{Cl}}$ - close to $0 \mathrm{mV}$, thereby facilitating the observation of $\mathrm{GABA}_{\mathrm{A}}$-mediated IPSCs at resting potentials. Whole cell currents were amplified and filtered ( 5 or $10 \mathrm{kHz} f_{\mathrm{c}}$ ) using an Axopatch 1D amplifier (Axon Instruments), digitized at $88 \mathrm{kHz}$ with a Neurocorder (DR-484, Neurodata, New York, NY), and stored on videocassettes for off-line analysis. Recordings were made at holding potentials $\left(V_{\mathrm{h}}\right)$ of -60 or $-50 \mathrm{mV}$. Current recordings were transferred to a personal computer by replaying in analog form; filtering at 1,2 , or $5 \mathrm{kHz}$; and sampling at 5 or $10 \mathrm{kHz}$ using Axon Instruments software and hardware (pClamp version 6.01, TL-1 DMA A/D interface).

IPSC amplitudes and kinetics were measured on individual, unaveraged events using pClamp. The effects of modulators on IPSC amplitude were assessed statistically using the Kolmogorov-Smirnov test (one-tailed) on cumulative amplitude distributions. The IPSC amplitude distributions were assembled for a given cell before and after the addition of the modulator. The maximum difference between the distributions was determined. The significance of this difference was determined by conversion to a $\chi^{2}$ distribution with $\mathrm{df}=2$ (Sigel 1956). $\chi^{2}$ values reflecting $P<0.05$ were deemed significant. Because $\mathrm{Zn}^{2+}$ reduced membrane noise and made it possible to observe smaller IPSCs than in controls, cumulative distributions were assembled and compared only from PSCs in zinc that were larger than or equal to the minimum size resolvable under control conditions. This approach was conservatively intended to minimize the likelihood of finding a difference in distributions based simply on a difference in detectability (i.e., only IPSCs with amplitudes that would be detectable under both control and experimental conditions were compared statistically). This same rationale was used to compare IPSC distributions in control solutions to those in flunitrazepam, which tended to increase baseline noise. However, by excluding the smallest observable IPSCs in the lowest noise conditions (e.g., in $\mathrm{Zn}^{2+}$ ), this approach overestimated the mean IPSC amplitude; therefore all references to mean IPSC amplitudes include all clearly detectable IPSCs. The amplitudes of currents evoked by exogenous GABA application were relatively long-lived $(2-10 \mathrm{~s})$ and were measured from hardcopies of current records or from an oscilloscope.

Three types of statistical tests were used in the analysis. Because IPSC amplitude distributions were extremely skewed, statistical comparisons of IPSC amplitude before and after modulator additions were done with Kolmogorov-Smirnov tests instead of $t$-tests. The mean IPSC amplitude values given are used to illustrate any amplitude effects by modulators and were not used to determine the significance of the effects. A $t$-test was used to assess the significance of changes in other IPSC characteristics (i.e., decay kinetics and amplitude of responses to GABA applications). The effect of modulators on IPSC frequency within cells (pre- vs. postmodulator) were assessed with a two-sample $\chi^{2}$ test. Significance levels were set at $P<0.05$.

The effects of benzodiazepine on spontaneous IPSC (sIPSC) decay kinetics were found to be more variable at room temperature than at $30-33^{\circ} \mathrm{C}$, thus only recordings in the warmed conditions were examined in detail. The decay kinetics of individual IPSCs were usually best described by two exponential components; therefore only events with visibly good two-component fits were collected for analysis. Analysis of decay kinetics was limited to events that showed clearly different fast and slow decay constants (differed by a factor of $\geq 4$ ) and whose individual component ampli- 
A
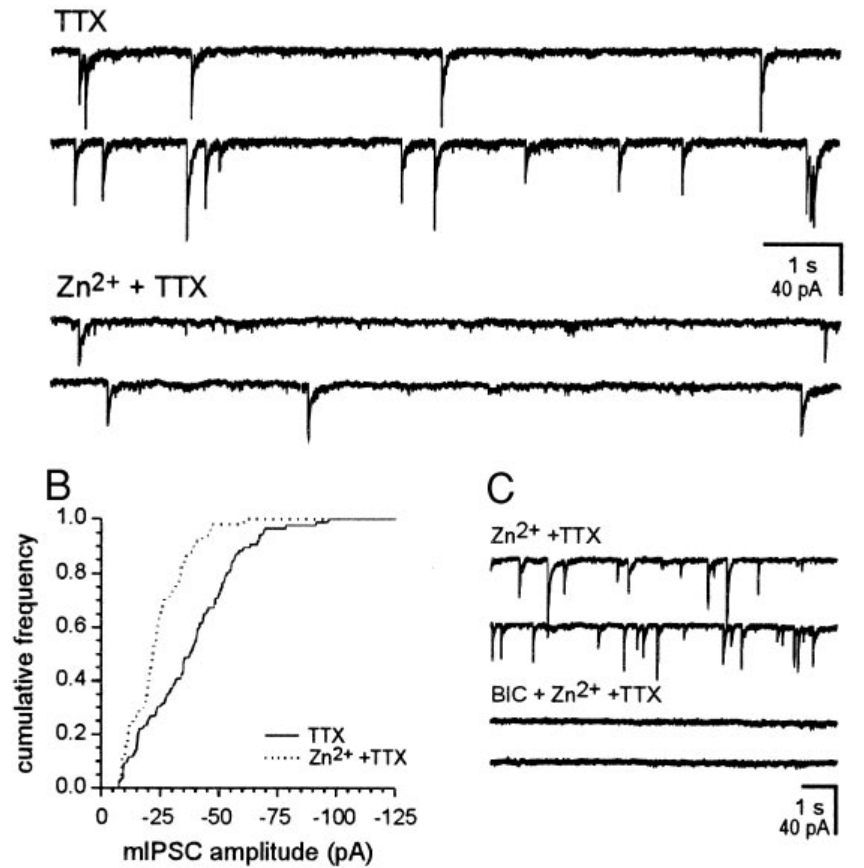

C
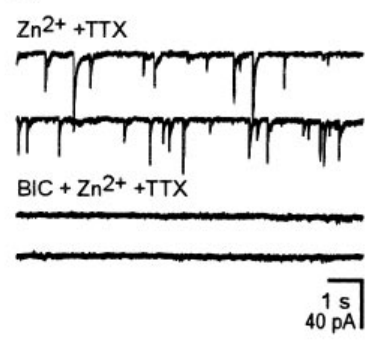

FIG. 1. Postsynaptic effects of zinc on GABAergic inhibitory postsynaptic currents (IPSCs). $A$ : effect of $\mathrm{Zn}^{2+}$ on miniature IPSCs (mIPSCs) in tetrodotoxin (TTX). Consecutive 8-s records in the presence of TTX (1 $\mu \mathrm{M})$ showed that $\mathrm{Zn}^{2+}(200 \mu \mathrm{M})$ reduced IPSC frequency and amplitude, suggesting a postsynaptic effect. Recorded neuron was from a 28-day-old rat and held at $V_{\mathrm{m}}-60 \mathrm{mV}$. $B$ : cumulative amplitude histograms of IPSCs with and without $\mathrm{Zn}^{2+}$ for the recording in $A$. $C: \gamma$-aminobutyric acid-A $\left(\mathrm{GABA}_{\mathrm{A}}\right)$ receptor antagonist bicuculline $(\mathrm{BIC} ; 20 \mu \mathrm{M})$ blocked all remaining $\mathrm{Zn}^{2+}$-attenuated mIPSCs. Consecutive 8 -s records are shown for each condition. All solutions contained 2-amino-5-phosphonovaleric acid (APV; $15 \mu \mathrm{M}$ ) and 6,7-dinitroquinoxaline-2,3(1h,4h)-dione (DNQX; 30 $\mu \mathrm{M})$ to block glutamate-mediated excitatory postsynaptic currents (EPSCs). Recorded neuron was from a 24-day-old rat and held at $V_{\mathrm{m}}-50$ $\mathrm{mV}$.

tudes comprised $\geq 20 \%$ of the total amplitude. Unusual events with exceptionally slow decay constants (typically $>2$ SD beyond average; i.e., $>300 \mathrm{~ms}$ ) were also excluded from collection and analysis. Effects of modulators on IPSC decay kinetics were assessed with a $t$-test.

\section{RESULTS}

\section{Effects of zinc}

The effects of bath application of zinc were examined on sIPSCs and on miniature IPSCs (mIPSCs). To examine whether the effects of $\mathrm{Zn}^{2+}$ were primarily postsynaptic, TTX was added to the bath solution to eliminate sodiumdependent action potentials. The remaining action potentialindependent mIPSCs were then examined in the absence and presence of zinc. The $\mathrm{GABA}_{\mathrm{A}}$-receptor-mediated mIPSCs were recorded in glutamate receptor antagonists AP5 and DNQX. The addition of $\mathrm{Zn}^{2+}(200 \mu \mathrm{M})$ significantly reduced the amplitude of mIPSCs in seven of eight cells (Kolmogorov-Smirnov test) to $54 \pm 5 \%$ (means \pm SE) of control mean amplitude (Fig. 1, $A$ and $B$ ). For an individual cell in each condition in the mIPSC experiments, an average of $174 \pm 31$ mIPSCs were measured over an average time of $214 \pm 11$ s. The one cell without a significant reduction showed a mean sIPSC amplitude in $\mathrm{Zn}^{2+}$ that was $94 \%$ of control, suggesting possible heterogeneity of receptor composition, and thus was excluded from further analysis of the effects of $\mathrm{Zn}^{2+}$ on mIPSC amplitude. $\mathrm{Zn}^{2+}$-induced amplitude reductions were significantly, but only partially, reversed after $\mathrm{Zn}^{2+}$ removal $(n=3)$. All mIPSCs remaining in the presence of $\mathrm{Zn}^{2+}$ were completely and reversibly blocked with the $\mathrm{GABA}_{\mathrm{A}}$-receptor antagonist bicuculline methiodide (30 $\mu \mathrm{M}, n=3$; Fig. $1 C$ ). These results indicate a primarily postsynaptic effect of zinc on IPSC amplitude.

In a set of experiments different from those on mIPSCs, $\mathrm{Zn}^{2+}(200 \mu \mathrm{M})$ also significantly reduced the mean amplitude of sIPSCs (without TTX) in four of five SCN neurons (Kolmogorov-Smirnov test). In the four cells showing significant reductions, mean sIPSC amplitudes were attenuated to $56 \pm 11 \%$ of control, whereas the one cell without a significant reduction showed a mean sIPSC amplitude in $\mathrm{Zn}^{2+}$ that was $96 \%$ of control, possibly indicating some heterogeneity of receptor composition. This cell was excluded from all further amplitude analyses. $\mathrm{Zn}^{2+}$ therefore reduced the amplitudes of mIPSCs and sIPSCs to a similar extent (to 54 and $56 \%$, respectively), further supporting the postsynaptic nature of this reduction. Thus for further examination of $\mathrm{Zn}^{2+}$ effects on IPSC amplitudes, mIPSCs and sIPSCs are considered together. Of 18 cells examined, 2 showed no zinc sensitivity (even at $200 \mu \mathrm{M}$, as noted above), so these data were excluded from dose-response analyses. The reduction of IPSCs by $\mathrm{Zn}^{2+}$ was concentration dependent (Fig. 2A). IPSC amplitudes were reduced to a mean fraction of 0.27 of control at $1,000 \mu \mathrm{M} \mathrm{Zn}^{2+}$. Higher concentrations of zinc were not examined because of the associated drop in frequency of measurable events.

$\mathrm{Zn}^{2+}$ has been shown in some preparations to cause giant synaptic potentials and synchronized synaptic release in GABAergic neurons (for review see Smart et al. 1994). In the $\mathrm{SCN}, \mathrm{Zn}^{2+}$ is reported to potentiate the A-current (Huang et al. 1993), which would tend to decrease neuronal firing frequency. Therefore we examined the effects of $\mathrm{Zn}^{2+}$ on IPSC frequency (Fig. $2 B$ ). Lower concentrations of $\mathrm{Zn}^{2+}(10$ and $50 \mu \mathrm{M})$ increased sIPSC frequency in most cells ( $4 / 5$ cells showed significant increases in 10 $\mu \mathrm{M} \mathrm{Zn}{ }^{2+} ; 5 / 5$ different cells showed significant increases at $50 \mu \mathrm{M})$. In contrast, sIPSC frequency was reduced at the highest concentration $(1,000 \mu \mathrm{M})$, which may have been caused by a $\mathrm{Zn}^{2+}$-induced decrease in the firing rate of afferent neurons or of synaptic GABA release. $\mathrm{Zn}^{2+}$ at $200 \mu \mathrm{M}$ produced on average no change in sIPSC frequency, but effects were highly variable with two cells showing significant increases, two showing decreases, and one with no significant effect ( $\chi^{2}$ test, 2 -sample), resulting in an average fractional change of $1.04 \pm 0.28(n=5)$. $\mathrm{Zn}^{2+}$ also significantly reduced the apparent frequency of mIPSCs in four of eight cells ( $\chi^{2}$ test, 2 -sample) to $69 \pm$ $10 \%$ of control, possibly by inhibiting spontaneous synaptic release, although it cannot be ruled out that some mIPSC amplitudes were reduced below detectability. Thus $\mathrm{Zn}^{2+}$ reduced mIPSC and sIPSC amplitude (particularly at 200 and $1,000 \mu \mathrm{M}$ ), but had a biphasic effect on sIPSC frequency, producing an increase at lower concentrations and decreasing the apparent frequency at $1,000 \mu \mathrm{M} . \mathrm{Zn}^{2+}$ at higher concentrations $(200-1,000 \mu \mathrm{M})$ tended to in- 
A

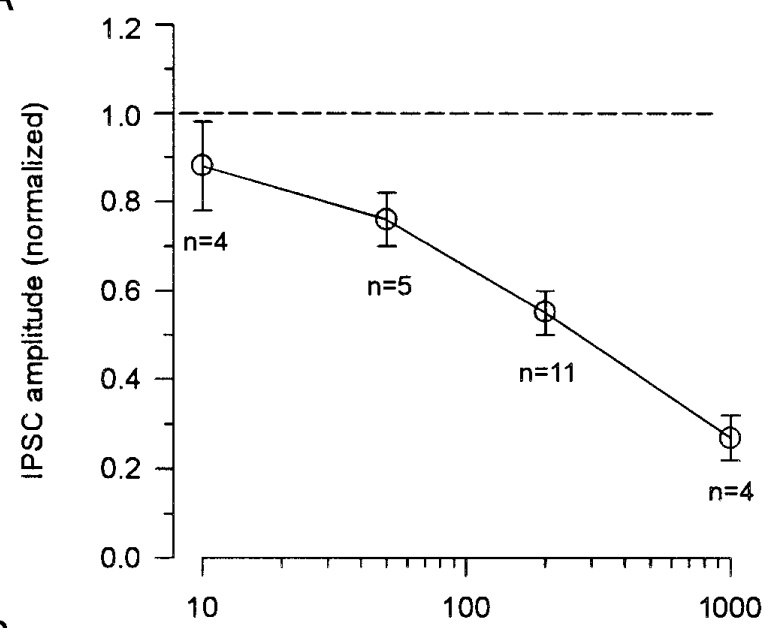

B

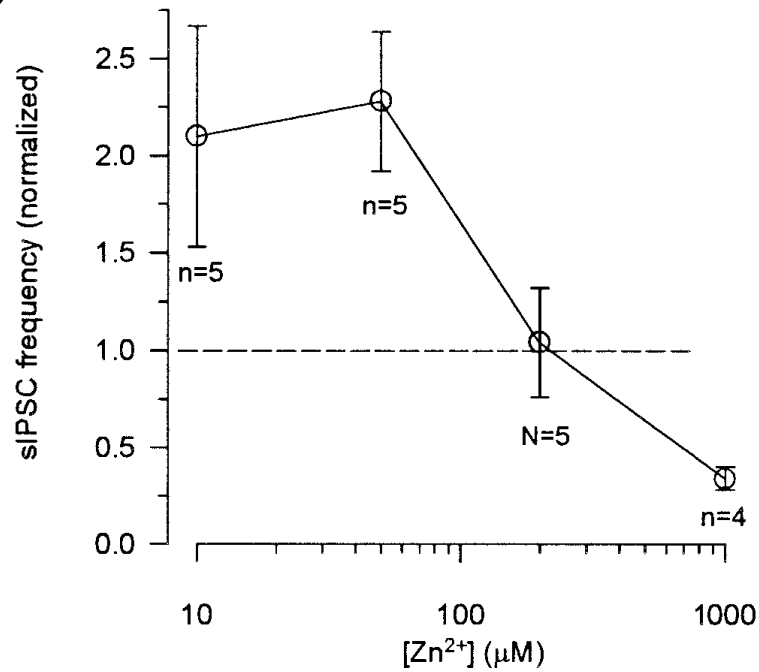

FIG. 2. Dose-dependent effects of $\mathrm{Zn}^{2+}$ on IPSC amplitude and frequency. $A$ : effect on IPSC amplitude. Relative amplitude of IPSCs (normalized to the control, pre- $\mathrm{Zn}^{2+}$ condition) is shown at 4 concentrations of $\mathrm{Zn}^{2+}$. B : effect on IPSC frequency. Relative frequency (normalized) of spontaneous IPSCs (sIPSCs) as a function of $\left[\mathrm{Zn}^{2+}\right]$ (these frequency data do not include experiments in TTX). - - - : normalized control level. For each cell in each condition, an average of $213 \pm 21$ IPSCs were measured over an average time of $204 \pm 9 \mathrm{~s}$ for $A$, and $235 \pm 28$ IPSCs over $198 \pm$ $13 \mathrm{~s}$ for $B$.

crease the mean resting potential from $-50.5 \pm 5.2 \mathrm{mV}$ to $-59 \pm 6.2 \mathrm{mV}$, but the effect did not reach statistical significance (paired $t$-test, 1 -tail, $P<0.1$ ). Such concentrations also produced a small, significant reduction in membrane noise from $2.21 \pm 0.09$ to $1.81 \pm 0.09 \mathrm{pA} \mathrm{rms}$.

To examine further the postsynaptic nature of $\mathrm{Zn}^{2+}$ block, we examined the responses of SCN neurons to exogenously applied GABA. Currents evoked by pressure-applied 100 $\mu \mathrm{M}$ GABA ( $200 \mu \mathrm{M}$ in 1 case) were reduced significantly when zinc was present $(200 \mu \mathrm{M})$ in eight of eight cells, to an average of $35 \pm 10 \%$ of their control amplitude ( $t$-test, 1-tail; an average of $6.3 \pm 0.6$ applications were examined per cell in each condition). Thus zinc proved an effective blocker of both endogenous ( synaptic) and exogenous (pressure-applied) GABA responses, indicating a postsynaptic effect.

\section{Effects of benzodiazepine}

The effect of flunitrazepam on currents evoked by pressure application of GABA was examined. Flunitrazepam (100 $\mathrm{nM}$ ) produced significant potentiation by an average of $242 \pm 22 \%$ in 13 of $13 \mathrm{SCN}$ neurons held at $30-32^{\circ} \mathrm{C}$ (Fig. $3, t$-test, 1-tail; an average of $7.1 \pm 0.4$ applications were examined in each condition per cell) and by an average of $193 \pm 10 \%$ in six of eight neurons at room temperature. Two neurons failed to show any potentiation by flunitrazepam at this temperature, suggesting possible heterogeneity in responsiveness to flunitrazepam. In general, the effects of flunitrazepam were more variable at room temperature than at $30-33^{\circ} \mathrm{C}$, therefore only experiments performed in heated solutions are considered further.

In contrast to its effects on exogenous GABA application, flunitrazepam usually failed to potentiate the amplitude of sIPSCs, producing significantly larger synaptic events in only 4 of 11 neurons (Kolmogorov-Smirnov test, an average

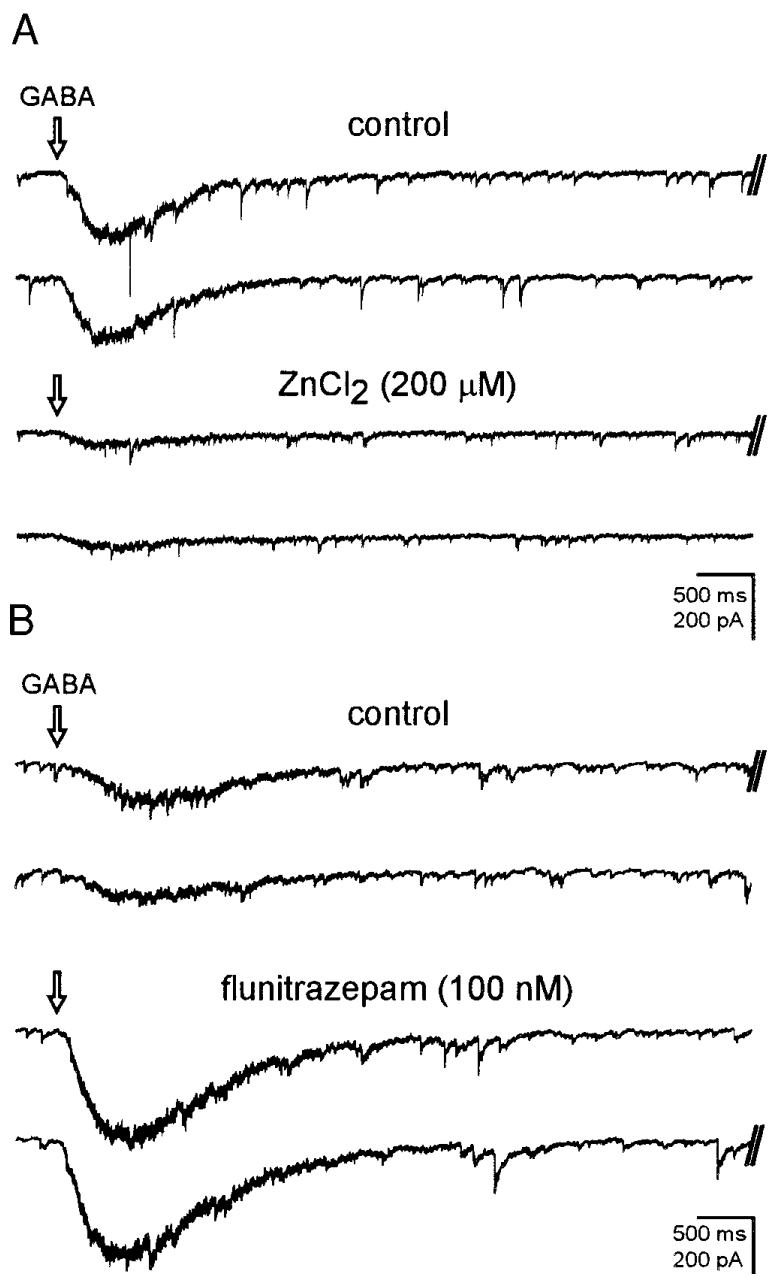

FIG. 3. Effect of $\mathrm{Zn}^{2+}$ and flunitrazepam on GABA response amplitudes. $A$ : recordings during consecutive applications of GABA $(100 \mu \mathrm{M}$ at arrow, applied every $30 \mathrm{~s})$ for control and $\mathrm{Zn}^{2+}(200 \mu \mathrm{M}) . B$ : recordings during consecutive applications of GABA ( $100 \mu \mathrm{M}$, applied every $15 \mathrm{~s})$ for control and flunitrazepam $(100 \mathrm{nM})$ in a different cell from $A$. Flunitrazepam had little effect on sIPSC amplitudes, in contrast to a strong potentiation of responses to pressure application of GABA. Traces are 650-ms segments taken from 2 consecutive GABA applications. Recordings were at $V_{\mathrm{m}}-60 \mathrm{mV}$. 

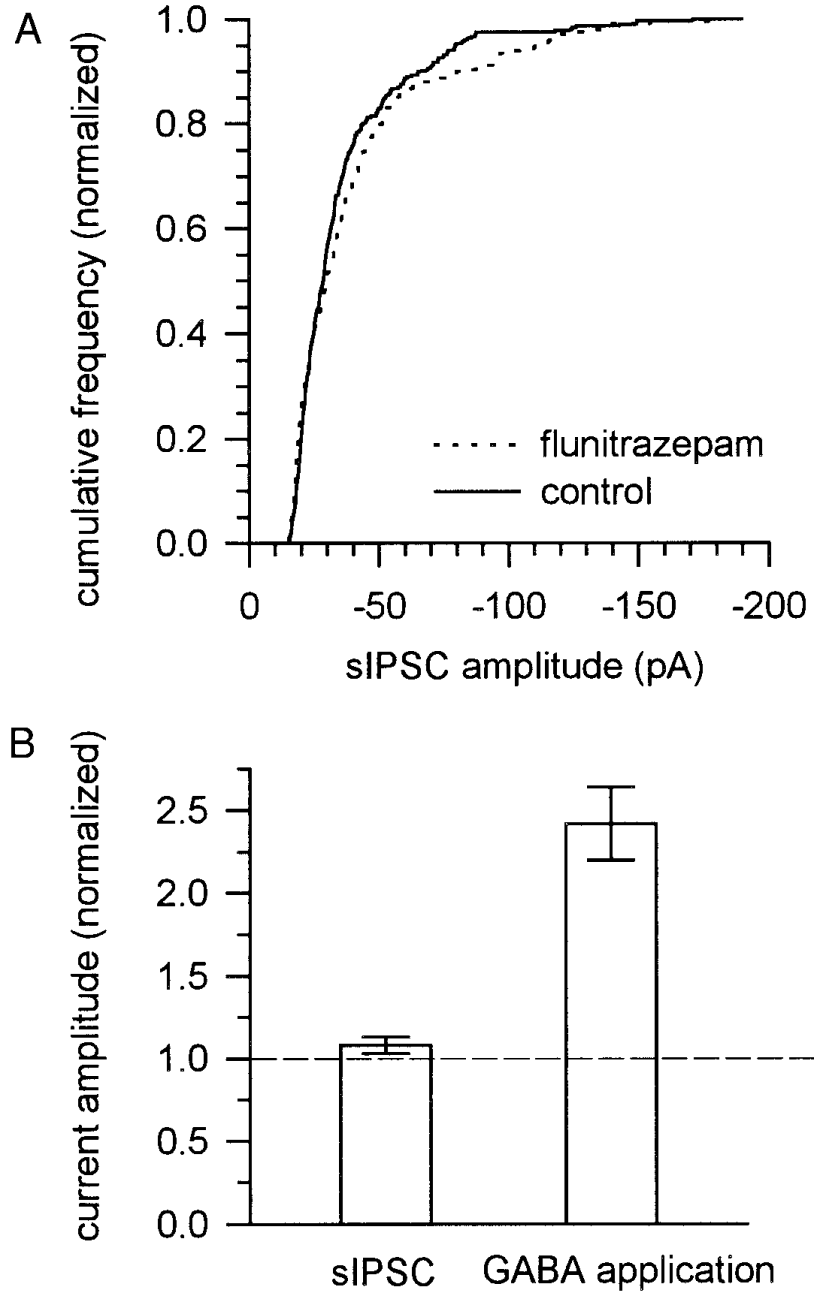

FIG. 4. Effect of flunitrazepam on amplitude of sIPSCs and response to exogenously applied GABA. A: cumulative frequency distribution of IPSC amplitudes reveals little effect of flunitrazepam (from cell shown in Fig. $3)$. $B$ : although IPSC amplitude was minimally potentiated $(n=11)$, currents evoked by GABA application were greatly enhanced $(n=13)$.

of $282 \pm 24$ sIPSCs were measured over an average time of $102 \pm 12 \mathrm{~s}$ for each of 11 cells in each condition). The mean amplitudes of sIPSCs in all 11 neurons in control and in $100 \mathrm{nM}$ flunitrazepam were $44.1 \pm 6.3$ and $47.2 \pm 6.2$ $\mathrm{pA}$, respectively, yielding an average fractional increase in sIPSC amplitude of $1.08 \pm 0.05$ (Fig. 4, $A$ and $B$; see also Fig. 3). Flunitrazepam also had variable effects on sIPSC frequency, decreasing it significantly in five cells, increasing it in one, and producing no significant change in five others ( $\chi^{2}$ test, 2-sample). Flunitrazepam tended to decrease the membrane potential from $-46.8 \pm 2.5$ to $-43.7 \pm 1.5 \mathrm{mV}$ (not significant: $P<0.1$ ) and significantly increased membrane current noise from $3.44 \pm 0.44$ to $4.15 \pm 0.38$ pA rms.

Although IPSC amplitude was only slightly affected, flunitrazepam significantly increased sIPSC decay constants. In control solutions, mean decay constants of $\tau_{\text {fast }}=7.5 \pm$ $0.7 \mathrm{~ms}$ and $\tau_{\text {slow }}=63.3 \pm 5.0 \mathrm{~ms}$ were found $(n=10)$, with a fractional amplitude $\left(\right.$ fract $\left._{\text {slow }}\right)=0.52 \pm 0.02$ for the slow component. When flunitrazepam $(100 \mathrm{nM})$ was added, all three parameters increased significantly $(P<$
0.005 , paired $t$-test, 1-tail) to different extents, yielding means of $\tau_{\text {fast }}=11.2 \pm 0.6 \mathrm{~ms}, \tau_{\text {slow }}=113.9 \pm 6.2 \mathrm{~ms}$, and fract $_{\text {slow }}=0.58 \pm 0.02$ (Fig. $5 A$ and $B$ legend). When the decay parameters were compared within individual cells ( $t$-test, 1-tail), flunitrazepam produced significant increases in $\tau_{\text {slow }}$ for all 10 neurons, whereas 7 of 10 showed significant increases in $\tau_{\text {fast }}$, and 5 of 10 showed significant increases in fract $_{\text {slow }}$. Thus benzodiazepine generally influenced all three of these decay parameters, but its main effect in terms of magnitude and reliability was on $\tau_{\text {slow }}$, which increased by an average factor of 1.9 ( significantly reversible in 3 of 3 cells). The increase in $\tau_{\text {slow }}$ was the greatest contributor to the prolongation of IPSCs with flunitrazepam.

\section{I S C U S S I ON}

$\mathrm{Zn}^{2+}$ and benzodiazepines can be effective modulators of GABAergic responses in the SCN. It has been suggested that zinc is present in the $\mathrm{SCN}$, possibly representing a synaptically releasable pool within presynaptic terminals $(\mathrm{Hu}-$ ang et al. 1993), and raising the possibility that it may act as an endogenous modulator. Benzodiazepines are commonly prescribed anxiolytics that can influence circadian behavior in rodent models. Reports on the effects of these modulators on SCN neurons have produced differing conclusions in the literature. We found that $\mathrm{Zn}^{2+}$ inhibited (in a dose-dependent manner) responses, produced by endogenous sources of

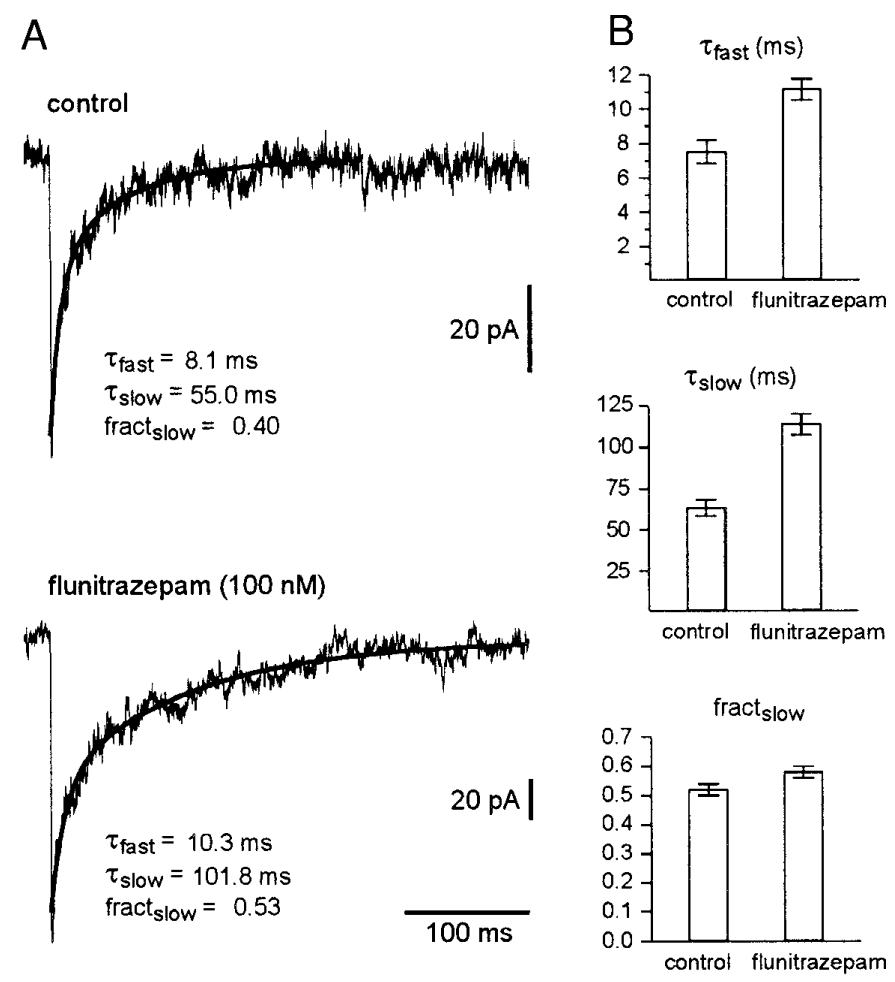

FIG. 5. Effect of flunitrazepam on kinetics of sIPSCs. A: flunitrazepam prolonged the decay of sIPSCs. Individual IPSCs from the same cell shown with superimposed 2-exponential fits, before and after the addition of flunitrazepam. $B$ : three kinetic parameters and IPSC amplitude were measured before and after the addition of flunitrazepam in 10 SCN neurons. Average values of the 2 decay constants (fast and slow) and their relative amplitude. All 3 kinetic parameters showed significant increases (paired $t$-test of within-cell means). An average of $24.5 \pm 2.4$ IPSCs were fitted individually for each condition in each cell. 
GABA (synaptic responses) and exogenous sources (pressure application of GABA), in nearly every cell examined. $\mathrm{Zn}^{2+}$ had a complex dose-dependent effect on the frequency of synaptic currents, indicating another modulatory effect. The benzodiazepine flunitrazepam prolonged sIPSC decay constants and potentiated responses to exogenous GABA in nearly every cell examined. Therefore most neurons in the SCN probably respond to both substances, which implies certain structural characteristics of $\mathrm{GABA}_{\mathrm{A}}$ receptor. Because of the richness of GABAergic synaptic connectivity within the SCN (Belenky et al. 1996; Strecker et al. 1997; van den Pol 1986), both substances are potentially able to modify the SCN neuronal network.

$\mathrm{Zn}^{2+}$ showed dose-dependent effects on the amplitude of $\mathrm{GABA}_{\mathrm{A}}$-mediated currents. The reduction of sIPSC amplitudes by $\mathrm{Zn}^{2+}$ probably reflects a postsynaptic effect on receptors, because mIPSCs were reduced to a similar degree by $\mathrm{Zn}^{2+}$ in the presence of TTX, and currents evoked by pressure application of GABA were also attenuated. However, the effect of $\mathrm{Zn}^{2+}(200 \mu \mathrm{M})$ on currents induced by pressure-applied GABA tended to be greater than on IPSCs (reduced to 35 vs. 55\%, respectively). There are several possibilities for this discrepancy. First, it is likely that $\mathrm{Zn}^{2+}$ reduced the amplitude of small IPSCs to below detectable levels, thus leaving preferentially the attenuated larger IPSCs to be measured and causing an underestimate of the reduction even when the better signal-to-noise ratio in $\mathrm{Zn}^{2+}$ is considered. Second, it is possible that $\mathrm{Zn}^{2+}$ did not diffuse sufficiently into the slice in the times allowed for recording or that SCN cells actively take up $\mathrm{Zn}^{2+}$ and produce a concentration gradient within the slice. Although we cannot dismiss these possibilities completely, IPSC amplitudes appeared to reach a steady state soon after addition of $\mathrm{Zn}^{2+}$, and our use of relatively thin slices should have contributed to more rapid diffusion. Third, although the $\mathrm{Zn}^{2+}$ block of $\mathrm{GABA}_{\mathrm{A}}$ receptors is often thought to be noncompetitive in central neurons, a recent report suggests that some subunit combinations are susceptible to competitive blocking by $\mathrm{Zn}^{2+}$ and produce a very different $\mathrm{IC}_{50}$ depending on the concentration of GABA used (Gingrich and Burkat 1998). Synaptic concentrations of GABA probably reach close to the milimolar range, but pressure application of $100 \mu \mathrm{M}$ GABA probably delivers substantially $<100 \mu \mathrm{M}$ to the SCN neuron in the slice, so synaptic responses, which are evoked by higher concentrations of GABA, would be less attenuated by $\mathrm{Zn}^{2+}$ during competitive block. It is also possible that dendrites and somata of SCN neurons have subtle differences in GABA receptors as far as $\mathrm{Zn}^{2+}$ block is concerned, but experiments designed specifically to address this question were not conducted.

Although our use of acute SCN slices provides advantages in terms of developmental and regional specificity and intact synaptic circuitry, the limitations for quantitative pharmacology described above suggest that our results are best viewed as an estimate for the minimum amount of block by $\mathrm{Zn}^{2+}$. Assuming that saturating concentrations of $\mathrm{Zn}^{2+}$ would completely attenuate our IPSC amplitudes, an $\mathrm{IC}_{50}$ near $200 \mu \mathrm{M}$ can be estimated for $\mathrm{Zn}^{2+}$ block as an upper bound (Fig. $2 A) . \mathrm{Zn}^{2+}$ has been shown to attenuate $\mathrm{GABA}_{\mathrm{A}}$ responses in some preparations (Mayer and Vyklicky 1989; Smart and Constanti 1990) but not in others (Smart and Constanti
1990). Our work demonstrates that $\mathrm{GABA}_{\mathrm{A}}$ responses in mature rat SCN neurons are almost always inhibited by $\mathrm{Zn}^{2+}$. In previous studies on SCN neurons, $\mathrm{Zn}^{2+}$ was found to block noncompetitively ( $\mathrm{IC}_{50}$ of $2 \mu \mathrm{M}$ ) the response to applied GABA in SCN neurons cultured from 21-day-old rats (Kawahara et al. 1993). Notwithstanding the potential underestimation of blocking strength for reasons described above, the difference between our $\mathrm{IC}_{50}$ estimate of $200 \mu \mathrm{M}$ and that of Kawahara et al. (1993) may be due to different populations of $\mathrm{GABA}_{\mathrm{A}}$ receptor, possibly related to culturing in the latter work.

$\mathrm{Zn}^{2+}$ had complex effects on sIPSC frequency, increasing it at lower concentrations while decreasing it at higher ones. The increased frequency of IPSCs found here at lower concentrations suggests that $\mathrm{Zn}^{2+}$ increases $\mathrm{SCN}$ neuronal excitability. In contrast, sIPSC amplitudes appear relatively less affected by such low concentrations of $\mathrm{Zn}^{2+}$, so it seems unlikely that an attenuation of endogenous GABAergic inhibition is entirely responsible for this increase in firing. The $\mathrm{A}$ current in SCN neurons was found to be potentiated (through shifts in inactivation voltage) by low concentrations of $\mathrm{Zn}^{2+}$ (Huang et al. 1993), but this effect would tend to reduce the firing rate. $\mathrm{Zn}^{2+}$ has been observed to produce synaptic potentiation and synchronous discharges in GABAergic neurons in other preparations, but the mechanisms of this effect are not well understood (for review see Smart et al. 1994). At higher concentrations of $\mathrm{Zn}^{2+}(1,000 \mu \mathrm{M})$, we found that the frequency of sIPSCs was decreased. This might indicate yet another mechanism of $\mathrm{Zn}^{2+}$ action on SCN neurons, although it is difficult to isolate postsynaptic from presynaptic effects in this case. One explanation for the apparent reduction in frequency relates to the decrease of IPSC amplitude. Another possibility is that high levels of $\mathrm{Zn}^{2+}$ interfere with presynaptic firing. Even when firing was blocked with TTX, however, $\mathrm{Zn}^{2+}(200 \mu \mathrm{M})$ significantly reduced the apparent frequency of mIPSCs (to $69 \%$ of control), whereas sIPSC frequency was not generally affected at this concentration (Fig. $2 B$ ). This raises the possibility that $\mathrm{Zn}^{2+}$ can attenuate synaptic release. Thus the effects of $\mathrm{Zn}^{2+}$ are complex and warrant further investigation.

Flunitrazepam significantly potentiated the responses to pressure-applied GABA in all $13 \mathrm{SCN}$ neurons from mature rats. Our result contrasts with a report in cultured SCN neurons where $\mathrm{GABA}_{\mathrm{A}}$-receptor-induced currents were found to be insensitive to benzodiazepine (Kawahara et al. 1993). More recent work in dissociated SCN neurons indicates that benzodiazepine potentiates $\mathrm{GABA}_{\mathrm{A}}$ currents (Shimura et al. 1996), but the young age of the SCN neurons (11-14 days) makes it difficult to extrapolate this result to the mature brain. The role of age in producing the experimental differences is not clear. Previous work reported that in hippocampal neuron slices a developmental change from low benzodiazepine sensitivity in neonates to higher sensitivity beyond 2 weeks of age (Rovira and Ben-Ari 1991). Thus whereas these contrasting studies raise interesting developmental issues in GABA receptor function in the SCN, ours appears to be the first study to describe the effects of benzodiazepine and $\mathrm{Zn}^{2+}$ on the mature SCN and confirms that these neurons are benzodiazepine sensitive. The source of the discrepancy involving benzodiazepine sensitivity might be because of the plasticity of cultured cells in the work of Kawahara et 
al. (1993). Due to of the relatively intact nature of SCN neurons in acute slices, our study allows better estimation of the behavior of dendritic GABA receptors than studies with dissociated neurons, although we cannot know precisely which currents originated in dendrites and which originated on the somata.

Flunitrazepam generally had little effect on SIPSC amplitudes, but consistently prolonged their decay constants. The fact that flunitrazepam failed to strongly potentiate IPSC amplitude suggests that similar numbers of GABA channels are activated initially during the brief synaptic release of GABA that generates the IPSC. Once activated, however, the channel opening frequency is increased by benzodiazepine (Rogers et al. 1994), which would produce longer decays. This model is consistent with the one proposed to explain the similar effects benzodiazepine on IPSCs in the hippocampus (Otis and Mody 1992). Flunitrazepam tended to decrease the sIPSC frequency (observed in 5/11 cells), suggesting that potentiation of GABAergic inhibition in the slice suppresses firing rates.

The sIPSC decays were usually best fitted with two exponential components $(\sim 7$ and $60 \mathrm{~ms}$ in control solutions at $\sim 31^{\circ} \mathrm{C}$ ). Single-exponential IPSC decays were also found but were in the minority and were not considered further. Previous findings have reported single decay components in IPSCs (Jiang et al. 1997; Otis and Mody 1992) or two decay components (Borst et al. 1994; Edwards et al. 1990). A single fast decay $(\sim 4.3 \mathrm{~ms})$ was reported in hippocampal granule cells at $35^{\circ} \mathrm{C}$, although two components $(\sim 2$ and 18 $\mathrm{ms}$ ) could be detected at $22^{\circ} \mathrm{C}$, and IPSC decays appeared temperature-sensitive in that study, with a $Q_{10}$ of 2.1 (Otis and Mody 1992). Two IPSC decay components were described in hippocampal granule cells at room temperature, but the second component was substantially longer $(\sim 60$ ms ) (Edwards et al. 1990) than in the previous study. Cerebellar granule cell IPSCs showed two-component IPSC decays as well ( $\sim 7$ and $60 \mathrm{~ms}$ ) at room temperature, whereas Purkinje neurons had faster single exponential decays $(\sim 8$ ms) (Puia et al. 1994). Cultured hippocampal neurons showed two components in averaged IPSCs at room temperature (50 and $171 \mathrm{~ms}$ ) (Jones and Westbrook 1995). Thus IPSCs' duration can vary extensively with experimental condition and neuron type. Surprisingly, however, our IPSC decays were very different from those observed in the SCN by Jiang et al. (1997), who reported one decay constant of $\sim 7 \mathrm{~ms}$ at $36^{\circ} \mathrm{C}$, which is similar to our fast component (they mentioned no 2nd component). Postsynaptic current kinetics depend in part on the degree to which voltage is adequately controlled. Our IPSC rise times $(10-90 \%$ rise time of $0.56 \pm 0.05 \mathrm{~ms}$ measured on individual IPSCs; $n=5$ cells in control solutions) appeared to be faster, however, than those of Jiang et al. (1997), who reported IPSC rise times of $2.2 \pm 0.7 \mathrm{~ms}$, suggesting that differences in voltage- or space-clamp control are not primarily responsible for this difference. At present it is unclear what the source of the discrepancy might be.

These findings have implications about the subunit composition of $\mathrm{GABA}_{\mathrm{A}}$ receptors in the SCN. Low sensitivity to benzodiazepines has been associated with $\mathrm{GABA}_{\mathrm{A}}$ receptors lacking the $\gamma_{2}$ subunit (Pritchett et al. 1989; Sigel et al. 1990), and the presence of $\gamma$ subunits has been shown to lower the susceptibility to block by $\mathrm{Zn}^{2+}$ (Draguhn et al. 1990). Furthermore, mutant mice generated without the $\gamma_{2}$ subunit show GABA currents that are not potentiated by flunitrazepam but are highly sensitive to zinc, in contrast to control mice (Günther et al. 1995). On the basis of these studies, the work in the $\mathrm{SCN}$ showing high $\mathrm{Zn}^{2+}$ sensitivity and no response to diazepam (Kawahara et al. 1993) suggests a $\gamma$-less phenotype of $\mathrm{GABA}_{\mathrm{A}}$ receptor, whereas a contrasting study showing diazepam sensitivity in young SCN neurons (Shimura et al. 1996) suggests the presence of a $\gamma_{2}$ subunit. Our findings in the mature SCN of benzodiazepine sensitivity and moderate zinc sensitivity suggest the presence of $\gamma_{2}$ subunits in this region, which is consistent with studies involving mRNA expression (O'Hara et al. 1995) and immunohistochemical evidence (Gao et al. 1995). Because of the technical difficulties of providing a high degree of control of concentration and rapid application in intact brain slices, we are unable to resolve more subtle characteristics of these receptors, which would help reveal other subunits than $\gamma_{2}$ that are present in these $\mathrm{GABA}_{\mathrm{A}}$ receptors. Single-channel or rapid-application experiments in isolated membrane patches from slices with more specific ligands could help to dissect out more precisely which subunit combinations are assembled in the mature SCN.

Our results demonstrate at a cellular level that both $\mathrm{Zn}^{2+}$ and benzodiazepine are effective modulators of adult $\mathrm{SCN}$ neurons. An understanding of their role in the SCN and circadian behavior is complicated by the presence of $\mathrm{GABA}_{\mathrm{A}}$-receptor-mediated interconnections within the nucleus (Strecker et al. 1997) and the recent but controversial report that GABA may be predominantly excitatory during the day (Wagner et al. 1997). It is unclear whether endogenous $\mathrm{Zn}^{2+}$ plays a modulatory role in the $\mathrm{SCN}$, but the increase in IPSC frequency produced by low concentrations of this ion suggests that $\mathrm{Zn}^{2+}$ could be highly effective in the SCN. By decreasing sIPSC frequency and amplitude, $\mathrm{Zn}^{2+}$ at higher concentrations would be expected to reduce the effectiveness of the local GABAergic system in the SCN. Benzodiazepines are known to have effects on circadian rhythmicity, and our study demonstrates direct actions of this drug on spontaneous synaptic activity in the SCN. The prolongation of IPSC decay by benzodiazepine (to $113 \mathrm{~ms}$ ) suggests that even if SCN neurons receive synaptic input from only one other SCN neuron firing at a normal daytime rate of $5-10 \mathrm{~Hz}$, benzodiazepine would tend to convert solitary IPSCs to ones showing temporal summation. Thus benzodiazepine would enhance the effectiveness of the local GABAergic circuit in the SCN.

Present address of W. K. Park: Dept. of Physiology, Keimyung University School of Medicine, 194 Dongsan-dong, Choong-gu, Taegu 700-310, Korea.

Address reprint requests to F. E. Dudek.

Received 2 June 1998; accepted in final form 29 September 1998.

\section{REFERENCES}

Belenky, M., Wagner, S., Yarom, Y., Matzner, H., Cohen, S., and CASTEL, M. The suprachiasmatic nucleus in stationary organotypic culture. Neuroscience 70: 127-143, 1996.

Borst, J.G.G., LODDER, J. C., AND KITS, K. S. Large amplitude variability of GABAergic IPSCs in melanotropes from Xenopus laevis: evidence 
that quantal size differs between synapses. J. Neurophysiol. 71: 639655, 1994.

Bos, N.P.A. AND Mirmiran, M. Effects of excitatory and inhibitory amino acids on neuronal discharges in the cultured suprachiasmatic nucleus. Brain Res. Bull. 31: 67-72, 1993.

Draguhn, A., Verdoorn, T. A., Ewert, M., Seeburg, P. H., and SaKMANN, B. Functional and molecular distinction between recombinant rat $\mathrm{GABA}_{\mathrm{A}}$ receptor subtypes by $\mathrm{Zn}^{2+}$. Neuron 5: 781-788, 1990.

Edwards, F. A., Konnerth, A., And Sakmann, B. Quantal analysis of inhibitory synaptic transmission in the dentate gyrus of rat hippocampal slices: a patch-clamp study. J. Physiol. (Lond.) 430: 213-249, 1990.

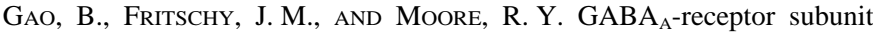
composition in the circadian timing system. Brain Res. 700: 142-156, 1995.

GingRich, K. J. AND BURKat, P. M. $\mathrm{Zn}^{2+}$ inhibition of recombinant $\mathrm{GABA}_{\mathrm{A}}$ receptors: an allosteric, state-dependent mechanism determined by the $\gamma$-subunit. J. Physiol. (Lond.). 506: 609-625, 1998.

Gribkoff, V. K., Pieschl, R. L., Wisialowski, T. A., AND Dudek, F. E. Effects of GABA and GABA-receptor antagonists on neuronal discharge and circadian rhythmicity in the rat suprachiasmatic nucleus in vitro. Soc. Neurosci. Abstr. 23: 241, 1997.

Günther, U., Benson, J., Benke, D., Fritschy, J.-M., Reyes, G., Knoflach, F., Crestani, F., Aguzzi, A., Arigoni, M., Lang, Y., BluETHMANN, H., MOHLER, H., AND LÚsCHER, B. Benzodiazepine-insensitive mice generated by targeted disruption of the $\gamma_{2}$ subunit gene of $\gamma$-aminobutyric acid type A receptors. Proc. Natl. Acad. Sci. USA 92: 77497753, 1995.

Huang, R.-C., Peng, Y.-W., And Yau, K.-W. Zinc modulation of a transient potassium current and histochemical localization of the metal in neurons of the suprachiasmatic nucleus. Proc. Natl. Acad. Sci. USA 90: 11806-11810, 1993.

JiANG, Z. G., YANG, Y., LiU, Z.-P., AND Allen, C. N. Membrane properties and synaptic inputs of suprachiasmatic nucleus neurons in rat brain slices. J. Physiol. (Lond.) 499: 141-159, 1997.

Jones, M. V. And WestbrooK, G. L. Desensitized states prolong GABA $A_{A}$ channel responses to brief agonist pulses. Neuron 15: 181-191, 1995.

Kawahara, F., Saito, H., and Katsuki, H. Pharmacological characteristics of $\mathrm{GABA}_{\mathrm{A}}$ responses in postnatal suprachiasmatic neurons in culture. Neurosci. Lett. 160: 45-48, 1993.

KIM, Y. I. AND DUDEK, F. E. Intracellular electrophysiological study of suprachiasmatic nucleus neurones in rodents: inhibitory synaptic mechanisms. J. Physiol. (Lond.). 458: 247-260, 1992.

Liou, S. Y., Shibata, S., Albers, H. E., and Ueki, S. Effects of GABA and anxiolytics on the single unit discharge of suprachiasmatic neurons in rat hypothalamic slices. Brain Res. Bull. 25: 103-107, 1990.

Mason, R., Biello, S. M., and Harrington, M. E. The effects of GABA and benzodiazepines on neurones in the suprachiasmatic nucleus (SCN) of Syrian hamsters. Brain Res. 552: 53-57, 1991.

MAYER, M. L. AND VyKLICKY, L., JR. The action of zinc on synaptic transmission and neuronal excitability in cultures of mouse hippocampus. J. Physiol. (Lond.) 415: 351-365, 1989.

MeIJER, J. H. AND RIETVELD, W. J. Neurophysiology of the suprachiasmatic circadian pacemaker in rodents. Physiol. Rev. 69: 671-707, 1989.

MoORE, R. Y. AND SPEH, J. C. GABA is the principal neurotransmitter of the circadian system. Neurosci. Lett. 150: 112-116, 1993.

Morin, L. P. Neural control of circadian rhythms as revealed through the use of benzodiazepines. In: Suprachiasmatic Nucleus The Minds Clock, edited by D. C. Klein, R. Y. Moore, and S. M. Reppert. London: Oxford Press, 1991, p. 324-338.

O'Hara, B. F., Andretic, R., Heller, H. C., Carter, D. B., ANd KildufF, T. S. $\mathrm{GABA}_{\mathrm{A}}, \mathrm{GABA}_{\mathrm{C}}$, and NMDA receptor subunit expression in the suprachiasmatic nucleus and other brain regions. Mol. Brain Res. 28: 239-250, 1995.

Otis, T. S. AND Mody, I. Modulation of decay kinetics and frequency of
$\mathrm{GABA}_{\mathrm{A}}$ receptor-mediated spontaneous inhibitory postsynaptic currents in hippocampal neurons. Neuroscience. 49: 13-32, 1992.

PritchetT, D. B., LüdDens, H., And Seeburg, P. H. Type I and type II $\mathrm{GABA}_{\mathrm{A}}$-benzodiazepine receptors produced in transfected cells. Science 245: 1389-1392, 1989.

Puia, G., Costa, E., AND Vicini, S. Functional diversity of GABA-activated $\mathrm{Cl}^{-}$currents in Purkinje versus granule neurons in rat cerebellar slices. Neuron 12: 117-126, 1994.

Puia, G., Vicini, S., SeEburg, P. H., And Costa, E. Influence of recombinant $\gamma$-aminobutyric acid-A receptor subunit composition on the action of allosteric modulators of $\gamma$-aminobutyric acid-gated $\mathrm{Cl}^{-}$currents. Mol. Pharmacol. 39: 691-696, 1991.

RalPh, M. R. and MenaKeR, M. Effects of diazepam on circadian phase advances and delays. Brain Res. 372: 405-408, 1986.

RALPH, M. R. AND MENAKER, M. GABA regulation of circadian responses to light. I. Involvement of $\mathrm{GABA}_{\mathrm{A}}$-benzodiazepine and $\mathrm{GABA}_{\mathrm{B}}$ receptors. J. Neurosci. 9: 2858-2865, 1989.

Rogers, C. J., Twyman, R. E., and MacDonald, R. L. Benzodiazepine and $\beta$-carboline. regulation of single $\mathrm{GABA}_{\mathrm{A}}$ receptor channels of mouse spinal neurones in culture. J. Physiol. (Lond.). 475: 69-82, 1994.

ROVIRA, C. AND BEN-ARI, Y. Benzodiazepines do not potentiate GABA responses in neonatal hippocampal neurons. Neurosci. Lett. 130: 157$161,1991$.

RUSAK, B. AND BINA, K. G. Neurotransmitters in the mammalian circadian system. Annu. Rev. Neurosci. 13: 387-401, 1990.

Shimura, M., Harata, N., TAmai, M., AND AKaIKe, N. Allosteric modulation of $\mathrm{GABA}_{\mathrm{A}}$ receptors in acutely dissociated neurons of the suprachiasmatic nucleus. Am. J. Physiol. 270 (Cell Physiol. 40): C1726-C1734, 1996.

Sigel, E., Baur, R., Trube, G., Möhler, H., and Malherbe, P. The effect of subunit composition of rat brain $\mathrm{GABA}_{\mathrm{A}}$ receptors on channel function. Neuron 5: 703-711, 1990.

Sigel, S. Nonparametric Statistics for the Behavioral Sciences. New York: McGraw-Hill, 1956, p. 131.

SIEGHART, W. Molecular basis of pharmacological heterogeneity of GABA receptors. Cell. Signal. 4: 231-237, 1992.

Smart, T. G. and Constanti, A. Differential effect of zinc on the vertebrate GABA ${ }_{\mathrm{A}}$-receptor complex. Br. J. Pharmacol. 99: 643-654, 1990.

Smart, T. G., Xie, X., AND KrisheK, B. J. Modulation of inhibitory and excitatory amino acid receptor ion channels by zinc. Prog. Neurobiol. 42: 393-441, 1994.

Smith, R. D., InOuYe, S.-I.T., AND TuREK, F. W. Central administration of muscimol phase-shifts the mammalian circadian clock. J. Comp. Physiol. [A]. 164: 805-814, 1989.

Strecker, G. J., PARK, W. K., AND Dudek, F. E. GABA-mediated inhibition of neuronal firing in the rat suprachiasmatic nucleus during circadian day. Soc. Neurosci. Abstr. 24: 1917, 1998.

Strecker, G. J., WuARIN, J.-P., AND Dudek, F. E. GABA $A_{\mathrm{A}}$-mediated local synaptic pathways connect neurons in the rat suprachiasmatic nucleus. J. Neurophysiol. 78: 2217-2220, 1997.

TuReK, F. W. AND VAn ReETH, O. Altering the mammalian circadian clock with the short-acting benzodiazepine, triazolam. Trends Neurosci. 11: 535-541, 1988.

VAN DEN POL, A. Gamma-aminobutyrate, gastrin releasing peptide, serotonin, somatostatin, and vasopressin: ultrastructural immunocytochemical localization in presynaptic axons in the suprachiasmatic nucleus. Neuroscience 17: 643-659, 1986.

Verdoorn, T. A., Draguhn, A., Ymer, S., Seeburg, P. H., and Sakmann, B. Functional properties of recombinant rat $\mathrm{GABA}_{\mathrm{A}}$ receptors depend upon subunit composition. Neuron 4: 919-928, 1990.

Wagner, S., Castel, M., Gainer, H. and Yarom, Y. GABA in the mammalian suprachiasmatic nucleus and its role in diurnal rhythmicity. Nature 387: 598-603, 1997.

Wisden, W., Laurie, D. J., Monyer, H., and Seeburg, P. H. The distribution of $13 \mathrm{GABA}_{\mathrm{A}}$ receptor subunit mRNAs in the rat brain. I. telencephalon, diencephalon, mesencephalon. J. Neurosci. 12: 1040-1062, 1992. 